\title{
BMJ Open Medical benefits in young adulthood: a population-based longitudinal study of health behaviour and mental health in adolescence and later receipt of medical benefits
}

\author{
Åse Sagatun, ${ }^{1}$ Sonja Heyerdahl, ${ }^{1}$ Tore Wentzel-Larsen, ${ }^{1,2}$ Lars Lien ${ }^{3,4}$
}

To cite: Sagatun $\AA$, Heyerdahl S, WentzelLarsen T, et al. Medical benefits in young adulthood: a population-based longitudinal study of health behaviour and mental health in adolescence and later receipt of medical benefits. BMJ Open 2015;5:e007139. doi:10.1136/bmjopen-2014007139

- Prepublication history and additional material is available. To view please visit the journal (http://dx.doi.org/ 10.1136/bmjopen-2014007139).

Received 7 November 2014 Revised 11 April 2015 Accepted 16 April 2015

CrossMark

For numbered affiliations see end of article.

Correspondence to Dr Åse Sagatun; aase.sagatun@r-bup.no

\section{ABSTRACT}

Objectives: To examine the extent to which smoking, alcohol, physical activity and mental health problems in 15-16-year-olds are associated with receipt of medical benefits in young adulthood, after adjustment for confounders.

Design: Prospective population-based cohort survey linked to national registers.

Participants: In the 'Youth studies' from the Norwegian Institute of Public Health, 15966 10th graders in 6 Norwegian counties answered a health behaviour and mental health questionnaire; $88 \%$ were linked to National Insurance Administration Registers (FD-Trygd).

Outcome measure: Time to receipt of medical benefits, based on FD-Trygd. Follow-up was from age 18 years until participants were aged 22-26 years.

Method: We performed Cox regression analyses to examine the extent to which variations in health behaviour and mental health problems during 10th grade were associated with receipt of medical benefits during follow-up.

Results: Daily smoking at age 15-16 years was associated with a significant increase in hazard of receiving health benefits at follow-up compared with not smoking for boys, HR (95\% CI) 1.56 (1.23 to 1.98), and for girls 1.47 (1.12 to 1.93). Physical activity was associated with a decrease in hazard compared with inactivity from $23 \%$ to $53 \%$ in boys and from $21 \%$ to $59 \%$ in girls, while use of alcohol showed a mixed pattern. The hazard for benefits use rose with increasing levels of emotional symptoms, peer problems, conduct problems and hyperactivity-inattention problems (Strengths and Difficulties Questionnaire) at 15-16 years among both genders.

Conclusions: Health behaviour and mental health problems in adolescence are independent risk factors for receipt of medical benefits in young adulthood.

\section{INTRODUCTION}

Unemployment, use of social benefits, longterm sick leave and disability pension may all be pathways leading to social exclusion

\section{Strengths and limitations of this study}

Use of large population-based data material with a high response rate.

- Data from a survey in adolescence were combined with information on receipt of medical benefits from national registers.

- We could study independent effects of health behaviours and mental health problems after controlling for sociodemographic and family factors.

- No objective health measures were available, only self-reported health behaviour and mental health.

(marginalisation trajectory), which is experienced by an increasing number of young adults from Western countries. ${ }^{1}$ In Norway, the unemployment rate is low, but the proportion of young adults receiving social benefits because of health problems is of great concern. $^{2}$ The probability of returning to employment among young people receiving health-related benefits is low. ${ }^{2}$ Thus, the first years of adulthood are crucial for avoiding trajectories leading to long-term benefit dependency. It makes sense, from economic and social perspectives, to study predictors and pathways leading to use of sickness and disability benefits.

Adolescence is a key period for the adoption of health behaviour. Adolescence and puberty are also characterised by changes in mental health. ${ }^{3}$ The main reasons for receiving rehabilitation or disability benefits among young adults in Norway are primarily psychiatric disorders and secondarily musculoskeletal diagnoses. ${ }^{4}$ Among the population of 18-29-year-olds, almost 5\% received such benefits in 2008, a $38 \%$ increase since $1996 .{ }^{4}$

In adults, physical activity, ${ }^{5}$ smoking and alcohol consumption ${ }^{6-9}$ are associated with sick leave and disability pension. ${ }^{10}$ However, 
it is not clear how such health behaviours in adolescence may relate to receipt of health-related benefits in young adulthood. In addition, research on mental health and working life has generally focused on adult working populations. ${ }^{11} 12$ Some studies from Scandinavia have described an association between mental impairment/psychiatric diagnoses among young men at conscription (18 and 19 years) and later disability pension. ${ }^{13-15}$ A Norwegian study found that self-rated anxiety and depression in adolescence were associated with later use of health-related benefits. ${ }^{16}$ Studies outside Scandinavia have found that depression ${ }^{17} 18$ and conduct problems ${ }^{19}$ and disorders ${ }^{20}$ in adolescence are risk factors for low economic outcome and receipt of benefits. None of these papers have included health behaviour. In adolescence, mental health is related to health behaviours such as smoking, ${ }^{21}$ alcohol use $^{22}$ and physical activity. ${ }^{23}$ Thus, it is important to include both health behaviour and mental health in analyses exploring the independent effects of these factors.

Our large population-based sample of adolescents included self-reported survey data on several lifestyle factors, mental health problems and possible confounding factors including family variables. With the linkage to register data on medical benefits, we were able to study the independent effects of various health behaviours, as well as mental health problems, on marginalisation trajectories.

The aim of the study was to examine the extent to which smoking, alcohol consumption, physical activity and mental health problems during 10th grade (ages 15-16 years) were associated with use of medical benefits in young adulthood after adjusting for known confounders.

\section{METHODS}

\section{Data and linkages}

We used data from a large comprehensive survey of all 10th graders (age 15-16 years) in six Norwegian counties, linked to the high-quality National Insurance Administration Registers. The Norwegian Institute of Public Health conducted these health surveys between 1999 and $2004 .{ }^{24}$ The students completed two four-page questionnaires during two school classes. A project assistant was present in the classroom to inform the students about the survey and to administer the questionnaires. For those not present on the day of the survey, questionnaires, informed consent forms and a prestamped envelope were left at their school. Students who did not return the completed questionnaire during the school year were invited to do so in a letter sent to their home. The overall response rate to the questionnaire was $87 \%$ $(\mathrm{n}=15966)$. Of the participants at baseline, $88 \%$ $(n=14063)$ agreed to allow their survey data to be linked to official registers.

\section{Outcome measure: receipt of medical benefits}

Residents of Norway are all insured by the national insurance scheme. The outcome variable 'time to receiving a medical benefit' was based on registry data from the National Insurance Administration Registers (FD-Trygd). Adults with a history of impairing illness or long-standing reduced work ability could until March 2010 receive medical or vocational rehabilitation benefits with an aim to restore working ability. If their condition was severe and impaired their working capacity by $50 \%$ or more, they could be granted a temporary disability benefit. These three benefits were from March 2010 collapsed to one single benefit called AAP (work assessment allowance). A permanent disability benefit can be granted if the condition is severe, with a poor prognosis and if the working capacity is reduced by $50 \%$ or more. In the present study, medical and vocational rehabilitation benefits are defined as events. Follow-up began in the year that the participants turned 18 years and ended in February 2010, when participants were aged 2226 years. Individuals who emigrated (437) or died (33) during the study period were censored at that time. Individuals who emigrated or died before age 18 years were excluded from the analyses $(n=63)$. Also, individuals who received permanent or temporary disability benefits were excluded from the analyses $(n=26+4)$, because a majority of young people on disability pension have severe physical or mental disability from birth. ${ }^{25}$

\section{Health behaviour at age $15-16$ years}

Smoking habits were assessed with the question: 'Do you smoke, or have you smoked previously?' Possible answers were: 'no, never', 'yes, but I have stopped', 'yes, once in a while' and 'yes, daily'. Answers were categorised into: 'never/quit', 'once in a while' and 'daily'.

Alcohol consumption was estimated by asking how often in the course of the last year the person had been drinking alcohol. Possible answers were: 'not at all', 'a few times', 'once per month', '2-3 times per month', 'once per week' and '2-3 times per week or more'. 'Once per month' and '2-3 times per month' were analysed together as '1-3 times per month', and 'once per week' and '2-3 times per week or more' were collapsed into 'once a week or more'.

Physical activity includes various leisure time activities and both organised and unorganised activities. Participants were asked how many hours per week they spent on physical activity 'to an extent that makes you sweat and/or out of breath' outside of school. Possible answers were: $0,1-2$, $3-4,5-7,8-10$ and $11 \mathrm{~h}$ or more per week.

\section{Mental health at age 15/16 years}

Mental health problems were assessed using the self-report version of the Strengths and Difficulties Questionnaire (SDQ), a multi-informant wide-angle screening questionnaire. ${ }^{26} 27$ The SDQ has been used in a large number of population-based studies in several countries. ${ }^{27}$ It is a 25 -item questionnaire with five subscales, each consisting of five items, generating scores for emotional symptoms, conduct problems, hyperactivityinattention, peer problems and prosocial behaviour. 
Each item can be answered with 'not true' (0), 'somewhat true' (1) or 'certainly true' (2), with reference to the past 6 months. For each subscale, these values were summed to generate scale scores ranging from 0 to $10 .^{27}$ The four problem scales are used to study various symptoms of mental health problems at age 15-16 years. Cronbach's $\alpha$ was 0.70 for emotional symptoms, 0.49 for conduct problems, 0.60 for hyperactivity-inattention and 0.53 for peer problems. The SDQ is reported to be a genuinely dimensional measure of child mental health. ${ }^{28}$ When studying the associations with medical benefits, the SDQ subscales are used as continuous scores.

\section{Sociodemographic factors and family background}

The six counties represent both the south-east and north of Norway: Oppland (during the 2001/2002 school year, $\mathrm{n}=1754)$, Hedmark (2000/2001, $\mathrm{n}=1787)$, Oslo (2000/ 2001 and 1999/2000, $\mathrm{n}=6555)$, Nordland $(2003 / 2004$, $\mathrm{n}=2104)$, Troms $(2001 / 2002$ and 2003/2004, $\mathrm{n}=1290)$ and Finnmark (2002/2003, n=573).

Ethnic minorities Statistics Norway's definition of ethnic minorities, having both parents born in a country other than Norway, was used. ${ }^{29}$ Information about the parents' countries of birth was provided by register data from Statistics Norway. About 13\% of the sample had an ethnic minority background. Members of the Sami population, the indigenous population in northern Norway, are thus defined in these analyses as ethnic Norwegians if at least one parent was born in Norway.

Parents' education, registered when the participants were 15-16 years, was used. Parents' highest accomplished year of education was obtained from Statistics Norway's register on education. In the analyses, parents' education was categorised as 'compulsory education' ( $\leq 10$ th grade/lower secondary, 'intermediate education' (upper secondary), 'tertiary education' (University, up to 5 years) and 'tertiary education, more than 4 years' (longer University degree) ${ }^{30}$

Mother's and father's income, when the participant was aged 15-16 years, was obtained from Statistics Norway's register on income. Mother's and father's income ${ }^{31}$ was categorised as 'high' (above the 75th centile), 'medium' (25th-75th centile) or 'low' (below the 25th centile). In the multivariable regression analyses, income was entered as a continuous variable with Winsorisation of values above 2.5 million NOK (replacing values above this income by 2.5 million NOK, or about US $\$ 450000$ ) because of a highly skewed distribution.

Who the participants lived with was obtained from the questionnaire by asking 'Who do you live with now?'. Possible answers were: 'mum and dad', 'only mum', 'only dad', 'both (50/50)', 'mother/father with new partner', 'foster care' or 'others'. The variable was dichotomised into those who lived with mum and dad versus the others.

\section{Statistical analyses}

All analyses were stratified by gender. To describe the distribution of the background factors and health behaviour, cross-tab analysis was performed. The latter was also used to describe the rate of receipt of medical benefits in these strata. To study the correlations between health behaviours and mental health, we used Spearman's rank order correlation.

To examine the extent to which variations in health behaviour and mental health problems in 10th grade were associated with use of medical benefits during follow-up, we performed Cox regression analyses. In Cox regression, results are HRs, or ratios between instantaneous risks for the event being studied. We used multiple imputation to account for missing values in the independent variables. All the exposure and the time-to-event variables were included in the imputation. ${ }^{32}$ The first regression analyses were to test the univariate relationships of the three health behaviours and the four SDQ subscales with time to receiving health-related welfare benefits (crude model). In subsequent multivariable analyses, we first entered the health behaviours and the SDQ subscales separately and adjusted for sociodemographic factors (model 1, 7 analyses). Then, in the second step, the SDQ scales were entered separately and adjusted for health behaviour and sociodemographic factors (model 2, 4 analyses). In the third step, the health behaviours were entered together and also the sociodemographic factors (model 3, 1 analysis), and finally the SDQ subscales were also included in order to assess the relationships with health behaviour controlled for mental health (model 4, 1 analysis). The proportional hazard (PH) assumption was that the HRs were the same throughout the follow-up. The PH assumption was tested in multivariable models 2 and 4. First, a global $p$ value for deviations from the $\mathrm{PH}$ assumption was computed for the models as a whole. If significant, $\mathrm{p}$ values for deviations from $\mathrm{PH}$ for individual HRs were further investigated using a graphical procedure using smoothed plots of Schoenfeld residuals including confidence bands. ${ }^{33}$ To test for a possible non-linear relationship between the SDQ variables and time to receiving health-related welfare benefits, we re-estimated model 3 using restricted splines with four knots for the SDQ variables. ${ }^{32}$

Descriptive analyses were performed using SPSS V.22.0. Time-to-event analyses were performed using $\mathrm{R}$ (The $\mathrm{R}$ foundation for Statistical Computing, Vienna), the rms package for regression analyses, and Hmisc (function aregImpute) for generating multiply imputed data.

\section{RESULTS}

\section{Sample characteristics}

Of the study sample, $7.1 \%$ received medical benefits during follow-up. At the end of the follow-up, the percentage receiving medical benefits varied with ethnic background, county of residence, and parents' education, income and marital status among both genders (table 1).

Correlations between the SDQ subscales and health behaviours were 0.40 or lower within both genders, except between smoking and alcohol use among girls 
Table 1 Background characteristics and rate of medical benefits within groups in young adulthood $(n=13790)$

\begin{tabular}{|c|c|c|c|c|}
\hline & \multicolumn{2}{|c|}{ Boys $(n=6967)$} & \multicolumn{2}{|c|}{ Girls $(n=7003)$} \\
\hline & $\begin{array}{l}\text { Per cent } \\
\text { of sample }\end{array}$ & $\begin{array}{l}\text { Medical benefits } \\
\text { within groups }\end{array}$ & $\begin{array}{l}\text { Per cent } \\
\text { of sample }\end{array}$ & $\begin{array}{l}\text { Medical benefits } \\
\text { within groups }\end{array}$ \\
\hline Sample & & 7.6 & & 6.5 \\
\hline \multicolumn{5}{|l|}{ Sociodemographic factors } \\
\hline Ethnic background $\dagger$ & $(n=6967)$ & & $(n=7002)$ & \\
\hline Ethnic Norwegian & 86.1 & 7.1 & 87.3 & 6.4 \\
\hline 1st-generation immigrants & 7.8 & 13.1 & 8.1 & 8.0 \\
\hline 2nd-generation immigrants & 5.1 & 9.0 & 4.6 & 6.2 \\
\hline County of residence in Norway & $(n=6967)$ & & $(n=7003)$ & \\
\hline Oslo (born 1984/1985) & 46.4 & 8.1 & 46.8 & 6.3 \\
\hline Hedmark (1985) & 12.8 & 10.7 & 12.8 & 9.3 \\
\hline Oppland (1986) & 12.7 & 6.0 & 12.7 & 6.7 \\
\hline Nordland (1988) & 15.3 & 6.0 & 15.3 & 5.1 \\
\hline Troms $(1986 / 1987)$ & 8.7 & 6.6 & 8.7 & 6.2 \\
\hline Finnmark (1987) & 4.1 & 7.6 & 4.1 & 6.4 \\
\hline \multicolumn{5}{|l|}{ Family factors } \\
\hline Parents' education $\ddagger$ & $(n=6865)$ & & $(n=6904)$ & \\
\hline Compulsory & 13.9 & 13.9 & 13.2 & 10.7 \\
\hline Intermediate & 41.2 & 8.9 & 41.5 & 7.7 \\
\hline Tertiary & 31.3 & 4.9 & 30.9 & 3.1 \\
\hline Tertiary more than 4 years & 13.6 & 3.3 & 14.4 & 4.1 \\
\hline Father's income at age $16 \dagger$ & $(n=6550)$ & & $(n=6584)$ & \\
\hline Low & 33.9 & 10.5 & 32.8 & 9.6 \\
\hline Medium & 33.0 & 7.1 & 33.7 & 5.5 \\
\hline High & 33.1 & 4.5 & 33.6 & 4.1 \\
\hline Mother's income at age $16 \dagger$ & $(n=6831)$ & & $(n=6894)$ & \\
\hline Low & 33.4 & 9.9 & 33.2 & 7.6 \\
\hline Medium & 33.1 & 7.4 & 33.6 & 7.3 \\
\hline High & 33.5 & 5.1 & 33.2 & 4.3 \\
\hline Who do you live with? & $(n=6873)$ & & $(n=6988)$ & \\
\hline Mum and dad & 67.2 & 5.8 & 66.5 & 4.6 \\
\hline Mum or dad or other & 32.8 & 10.7 & 33.4 & 10.3 \\
\hline
\end{tabular}

$(\mathrm{r}=0.47)$ and between conduct and hyperactivity/inattention among boys $(\mathrm{r}=0.47)$ and girls $(\mathrm{r}=0.45)$.

\section{Associations of health behaviour and mental health in} 10th grade with receipt of medical benefits at follow-up Young adults who received medical benefits generally reported more unhealthy behaviours and mental health problems in 10th grade than those without any record of such benefits (table 2).

In Cox regression analysis (tables 3 and 4), we found that smoking increased the hazard of receiving medical benefits by $56 \%$ compared with no smoking in boys; among girls, the corresponding number was $47 \%$ when controlling for possible confounders, mental health and other health behaviours (table 3 , model 4). Being physically active reduced the likelihood of receiving medical benefits compared with no activity among both genders. There was a dose-response pattern, with a hazard reduction ranging from $23 \%$ to $53 \%$ in boys and from $21 \%$ to $59 \%$ in girls (tables 3 and 4, model 4). Never using alcohol in the last year was associated with an increased hazard of receiving health-related benefits than some use of alcohol among girls (1.41 (1.04 to 1.89) table 4, model 4). The same tendency was present among boys, but was statistically insignificant in the multivariable analysis (table 3). Weekly use of alcohol was also associated with an increased hazard of receiving medical benefits compared with some use in boys, but was not statistically significant in the final model when adjusting for mental health (HR=1.31 95\% CI 0.99 to 1.74 ). In girls, this association was no longer significant after adjusting for other health behaviours (model 3).

Symptoms of mental health problems in 10th grade predicted use of medical benefits at follow-up (tables 3 and 4), adjusted for sociodemographic variables and for health behaviour. For every point increase on the SDQ Peer problem scale, the hazard of receiving medical benefits increased by $15 \%$ in boys and by $26 \%$ in girls (tables 3 and 4, model 2). The corresponding figures for emotional symptoms were $10 \%$ and $17 \%$ for boys and girls, respectively. A one point increase in the Conduct problems scale increased the hazard by $19 \%$ in 
Table 2 Health behaviour and mental health (SDQ) in 10th grade according to medical benefits $(n=13970)$

\begin{tabular}{|c|c|c|c|c|c|c|c|c|}
\hline \multirow{3}{*}{$\begin{array}{l}\text { 10th Grade } \\
(1999-2004)\end{array}$} & \multicolumn{4}{|c|}{ Boys (6967) } & \multicolumn{4}{|c|}{ Girls (7003) } \\
\hline & \multicolumn{2}{|c|}{$\begin{array}{l}\text { No medical } \\
\text { benefits }\end{array}$} & \multicolumn{2}{|c|}{ Medical benefits } & \multicolumn{2}{|c|}{$\begin{array}{l}\text { No medical } \\
\text { benefits }\end{array}$} & \multicolumn{2}{|c|}{ Medical benefits } \\
\hline & $n^{\star}$ & Per cent & $n^{*}$ & Per cent & $n^{\star}$ & Per cent & $\overline{n^{*}}$ & Per cent \\
\hline \multicolumn{9}{|l|}{$\begin{array}{l}\text { Health behaviour in 10th grade } \\
\text { Smoking }\end{array}$} \\
\hline No & 4803 & 75.0 & 325 & 62.4 & 4401 & 67.6 & 245 & 53.7 \\
\hline Sometimes & 826 & 12.9 & 61 & 11.7 & 1096 & 16.8 & 77 & 16.9 \\
\hline Yes, every day & 771 & 12.0 & 139 & 26.5 & 1019 & 15.6 & 134 & 29.4 \\
\hline \multicolumn{9}{|l|}{ Alcohol consumed last year } \\
\hline Never & 1690 & 26.8 & 148 & 29.1 & 1473 & 22.8 & 117 & 25.6 \\
\hline A few times last year & 1721 & 27.3 & 108 & 21.2 & 1930 & 39.9 & 103 & 25.9 \\
\hline $1-3$ times a month & 2002 & 31.7 & 143 & 28.1 & 2175 & 33.7 & 155 & 34.4 \\
\hline Once a week or more & 894 & 14.2 & 110 & 21.6 & 871 & 13.5 & 76 & 16.9 \\
\hline \multicolumn{9}{|l|}{ Physical activity (h/week) } \\
\hline 0 & 552 & 8.7 & 88 & 17.8 & 698 & 11.0 & 102 & 23.4 \\
\hline $1-2$ & 1196 & 18.9 & 125 & 25.3 & 1918 & 30.3 & 162 & 37.2 \\
\hline $3-4$ & 1369 & 21.7 & 101 & 20.4 & 1918 & 30.3 & 88 & 20.2 \\
\hline $5-7$ & 1470 & 23.2 & 93 & 18.8 & 1272 & 20.1 & 59 & 13.6 \\
\hline 8 or more & 1736 & 27.5 & 188 & 17.8 & 701 & 11.1 & 24 & 5.5 \\
\hline SDQ & Mean & SD & Mean & SD & Mean & SD & Mean & SD \\
\hline Conduct problems & 2.23 & 1.67 & 3.12 & 1.94 & 1.91 & 1.40 & 2.61 & 1.75 \\
\hline Hyperactivity-inattention problems & 3.60 & 2.06 & 4.27 & 2.12 & 3.82 & 2.03 & 4.66 & 2.22 \\
\hline Emotional symptoms & 1.65 & 1.70 & 2.23 & 1.98 & 3.27 & 2.29 & 4.49 & 2.40 \\
\hline Peer problems & 1.70 & 1.54 & 2.23 & 1.76 & 1.50 & 1.49 & 2.33 & 1.89 \\
\hline
\end{tabular}

boys and by $21 \%$ in girls (tables 3 and 4, model 2). For hyperactivity-inattention problems, the corresponding figures were $11 \%$ in boys and $9 \%$ in girls.

The test for possible non-linear relationships between the SDQ scores and the dependent variable (time to receiving health-related benefits) showed that there were no significant deviations from a linear relationship for any genders ( $p$ for non-linearity $\geq 0.157$ ).

\section{The PH assumption}

The tests of the $\mathrm{PH}$ assumption indicated significant global deviations and significant deviations for some of the factors in some of the models. Graphical inspection of Schoenfeld residuals (including confidence bands) indicated that the hazard for peer problems was somewhat higher in the beginning and decreased during follow-up among both genders (model 2, see online supplementary figures S1 and S2). However, the deviation from $\mathrm{PH}$ was modest, and no analyses in separate time intervals were performed.

\section{DISCUSSION}

Daily smoking at 15-16 years increased the hazard of receiving health-related benefits in young adulthood compared with no smoking. Physical activity decreased the hazards of receiving benefits compared with inactivity, while the effect of use of alcohol was somewhat mixed. The hazard of receiving health-related benefits in young adulthood rose with increasing levels of various symptoms of mental health problems at 15-16 years.

These patterns were similar for boys and girls, and persisted in analyses controlling for sociodemographic and family factors.

\section{Methodological strengths and limitations}

The main strengths of the study were its utilisation of data from a large population-based sample of 10th graders, a high response rate, data on both health behaviour and various symptoms of mental health problems, and follow-up register data on the use of medical benefits.

Mental health problems and health behaviour were assessed by self-report, which may have been affected by a social desirability bias. However, in a study of the psychometric properties of the SDQ, the self-report problem scales for emotional symptoms, conduct problems and hyperactivity/inattention were all found to be associated with the relevant interview-based Diagnostic and Statistical Manual of Mental Disorders, Fourth Edition (DSM-IV) diagnoses. ${ }^{34}$ However, the discriminant validity between the emotional and peer subscales and between the conduct and hyperactivity-inattention subscales was found to be poorer in low-risk populations compared with high-risk populations. ${ }^{35}$ We study a 
Table 3 Health behaviour and mental health problems in 10th grade as predictors of medical benefits follow-up in boys $(n=6967)$

\begin{tabular}{|c|c|c|c|c|c|c|c|c|c|}
\hline \multicolumn{2}{|c|}{ Crude } & \multicolumn{2}{|c|}{ Model 1* } & \multicolumn{2}{|c|}{ Model $2 \dagger$} & \multicolumn{2}{|c|}{ Model 3‡ } & \multicolumn{2}{|c|}{ Model $4 \S$} \\
\hline HR & $95 \% \mathrm{Cl}$ & HR & $95 \% \mathrm{Cl}$ & HR & $95 \% \mathrm{Cl}$ & HR & $95 \% \mathrm{Cl}$ & HR & $95 \% \mathrm{Cl}$ \\
\hline
\end{tabular}

\begin{tabular}{|c|c|c|c|c|c|c|c|c|c|c|c|c|c|c|c|}
\hline \multicolumn{16}{|l|}{ Health behaviour } \\
\hline \multicolumn{16}{|l|}{ Smoking } \\
\hline No & ref. & & & ref. & & & & & & ref. & & & ref. & & \\
\hline Sometimes & 1.05 & 0.80 & 1.38 & 1.04 & 0.79 & 1.37 & & & & 0.99 & 0.75 & 1.32 & 0.92 & 0.69 & 1.23 \\
\hline Yes, every day & 2.52 & 2.07 & 3.08 & 2.08 & 1.70 & 2.55 & & & & 1.83 & 1.46 & 2.30 & 1.56 & 1.23 & 1.98 \\
\hline \multicolumn{16}{|c|}{ Alcohol consumed last year } \\
\hline Never & 1.34 & 1.04 & 1.71 & 1.20 & 0.93 & 1.55 & & & & 1.21 & 0.94 & 1.57 & 1.24 & 0.95 & 1.60 \\
\hline A few times last year & ref. & & & ref. & & & & & & ref. & & & ref. & & \\
\hline 1-3 times a month & 1.12 & 0.87 & 1.44 & 1.07 & 0.84 & 1.38 & & & & 0.96 & 0.74 & 1.24 & 0.92 & 0.71 & 1.19 \\
\hline Once a week or more & 1.80 & 1.38 & 2.34 & 1.82 & 1.40 & 2.37 & & & & 1.47 & 1.11 & 1.95 & 1.31 & 0.99 & 1.74 \\
\hline \multicolumn{16}{|l|}{ Physical activity (h/week) } \\
\hline 0 & ref. & & & ref. & & & & & & ref. & & & ref. & & \\
\hline $1-2$ & 0.65 & 0.50 & 0.86 & 0.65 & 0.50 & 0.86 & & & & 0.72 & 0.55 & 0.95 & 0.77 & 0.58 & 1.01 \\
\hline $3-4$ & 0.46 & 0.35 & 0.62 & 0.51 & 0.38 & 0.68 & & & & 0.56 & 0.42 & 0.75 & 0.63 & 0.47 & 0.84 \\
\hline $5-7$ & 0.40 & 0.30 & 0.54 & 0.46 & 0.34 & 0.61 & & & & 0.52 & 0.39 & 0.71 & 0.60 & 0.44 & 0.81 \\
\hline 8 or more & 0.33 & 0.24 & 0.44 & 0.38 & 0.28 & 0.51 & & & & 0.43 & 0.32 & 0.58 & 0.47 & 0.35 & 0.64 \\
\hline \multicolumn{16}{|l|}{$S D Q$} \\
\hline Conduct problems & 1.27 & 1.22 & 1.32 & 1.22 & 1.17 & 1.28 & 1.19 & 1.14 & 1.25 & & & & & & \\
\hline $\begin{array}{l}\text { Hyperactivity- } \\
\text { inattention problems }\end{array}$ & 1.16 & 1.12 & 1.21 & 1.13 & 1.09 & 1.18 & 1.11 & 1.06 & 1.15 & & & & & & \\
\hline Emotional symptoms & 1.17 & 1.12 & 1.22 & 1.12 & 1.08 & 1.17 & 1.10 & 1.06 & 1.15 & & & & & & \\
\hline Peer problems & 1.21 & 1.15 & 1.27 & 1.16 & 1.11 & 1.22 & 1.15 & 1.10 & 1.21 & & & & & & \\
\hline
\end{tabular}

*Model 1: Health behaviour and the SDQ subscales separately adjusted for ethnic background, county of residence, parents' education, income and marital status (seven analyses).

†Model 2: The SDQ subscales studied separately, adjusted for health behaviour, ethnic background, county of residence, parents' education, income and marital status (four analyses).

¥Model 3: Health behaviours together, adjusted for ethnic background, county of residence, parents' education, income and marital status (one analysis).

§Model 4: Health behaviours together, adjusted for the SDQ subscales and ethnic background, county of residence, parents' education, income and marital status (one analysis).

SDQ, Strengths and Difficulties Questionnaire.

normal population, and therefore do not highlight the difference between emotional and peer subscales, and between the conduct and hyperactivity subscales in the discussion of our findings. Imprecise measures of mental health and also health behaviour may have resulted in bias. We have no indication that measurement error in the exposure depends on the outcome and assume that our possible information bias is nondifferential. Non-differential errors have been considered to be less serious because the effect is most often biased in the direction of the null. ${ }^{36}{ }^{37}$ Thus, it is possible that the associations that we found of health behaviour and mental health with receiving health benefits during follow-up may be underestimated.

In our analysis, we excluded all participants receiving disability benefits because a majority of young people on disability pension have severe physical or mental disability from birth. ${ }^{4}$ We did this independent of granting time, and may have excluded some with incident disability during follow-up (eg, road traffic injuries, drug problems). However, the excluded disability pensioners were few in number $(n=30)$ with probably little impact on the results.
Another possible problem is that the exposure variables (health behaviour and SDQ) are collected at the same time. Relations between health behaviour and mental health are complex. Including both factors in a model could be a problem if one mediates the effect of the other. In the multivariable analyses, we have emphasised estimates where mental health scores are adjusted for background factors and health behaviours (model 2), and where health behaviour variables are controlled for one another and also mental health variables and background factors (model 4). However, we present estimates for health behaviour both without and with adjustment for mental health (models 3 and 4). By adjusting for mental health when studying the relationship of health behaviours with medical benefits, the relationships decreased somewhat. It is possible that we have underestimated the relationships in model 4.

Not all those who were invited participated in the 10th grade baseline assessment, and some did not agree to have their survey data linked to registry information. While a relatively high proportion $(76 \%)$ of the total 10th grade population was included in analyses, selection bias cannot be ruled out. However, this concern is ameliorated by the fact 
Table 4 Health behaviour and mental health problems in the10th grade as predictors of medical benefits follow-up in girls $(\mathrm{n}=7003)$

\begin{tabular}{|c|c|c|c|c|c|c|c|c|c|c|c|c|c|c|c|}
\hline & \multicolumn{3}{|c|}{ Crude } & \multicolumn{3}{|c|}{ Model 1* } & \multicolumn{3}{|c|}{ Model 2† } & \multicolumn{3}{|c|}{ Model 3} & \multicolumn{3}{|c|}{ Model 4} \\
\hline & HR & \multicolumn{2}{|c|}{$95 \% \mathrm{Cl}$} & $\overline{\text { HR }}$ & \multicolumn{2}{|c|}{$95 \% \mathrm{Cl}$} & $\overline{H R}$ & \multicolumn{2}{|c|}{$95 \% \mathrm{Cl}$} & HR & \multicolumn{2}{|c|}{$95 \% \mathrm{Cl}$} & HR & \multicolumn{2}{|c|}{$95 \% \mathrm{Cl}$} \\
\hline \multicolumn{16}{|l|}{ Smoking } \\
\hline No & ref. & & & ref. & & & & & & ref. & & & ref. & & \\
\hline Sometimes & 1.22 & 0.95 & 1.58 & 1.18 & 0.91 & 1.53 & & & & 1.29 & 0.98 & 1.70 & 1.19 & 0.90 & 1.56 \\
\hline Yes, every day & 2.31 & 1.87 & 2.85 & 1.82 & 1.46 & 2.29 & & & & 1.81 & 1.39 & 2.35 & 1.47 & 1.12 & 1.93 \\
\hline \multicolumn{16}{|c|}{ Alcohol consumed last year } \\
\hline Never & 1.41 & 1.08 & 1.84 & 1.45 & 1.09 & 1.93 & & & & 1.50 & 1.12 & 2.00 & 1.41 & 1.04 & 1.89 \\
\hline A few times last year & ref. & & & ref. & & & & & & ref. & & & ref. & & \\
\hline 1-3 times a month & 1.31 & 1.02 & 1.68 & 1.19 & 0.93 & 1.53 & & & & 1.01 & 0.78 & 1.31 & 1.03 & 0.79 & 1.35 \\
\hline Once a week or more & 1.53 & 1.14 & 2.06 & 1.56 & 1.15 & 2.10 & & & & 1.10 & 0.79 & 1.53 & 1.04 & 0.75 & 1.46 \\
\hline \multicolumn{16}{|l|}{ Physical activity (h/week) } \\
\hline 0 & ref. & & & ref. & & & & & & ref. & & & ref. & & \\
\hline $1-2$ & 0.59 & 0.46 & 0.75 & 0.66 & 0.52 & 0.86 & & & & 0.70 & 0.55 & 0.91 & 0.79 & 0.61 & 1.02 \\
\hline $3-4$ & 0.36 & 0.27 & 0.48 & 0.43 & 0.32 & 0.57 & & & & 0.46 & 0.35 & 0.62 & 0.56 & 0.41 & 0.75 \\
\hline $5-7$ & 0.34 & 0.24 & 0.46 & 0.41 & 0.30 & 0.57 & & & & 0.46 & 0.33 & 0.65 & 0.55 & 0.39 & 0.77 \\
\hline 8 or more & 0.25 & 0.16 & 0.39 & 0.32 & 0.20 & 0.50 & & & & 0.36 & 0.23 & 0.56 & 0.41 & 0.26 & 0.65 \\
\hline \multicolumn{16}{|l|}{$S D Q$} \\
\hline Conduct problems & 1.31 & 1.24 & 1.38 & 1.25 & 1.19 & 1.32 & 1.21 & 1.14 & 1.29 & & & & & & \\
\hline $\begin{array}{l}\text { Hyperactivity- } \\
\text { inattention problems }\end{array}$ & 1.22 & 1.17 & 1.27 & 1.17 & 1.12 & 1.23 & 1.14 & 1.09 & 1.20 & & & & & & \\
\hline Emotional symptoms & 1.22 & 1.26 & 1.38 & 1.19 & 1.15 & 1.24 & 1.17 & 1.13 & 1.21 & & & & & & \\
\hline Peer problems & 1.32 & 1.26 & 1.38 & 1.27 & 1.21 & 1.34 & 1.26 & 1.20 & 1.32 & & & & & & \\
\hline $\begin{array}{l}{ }^{*} \text { Model 1: Health behaviour } \\
\text { income and marital status } \\
\text { †Model 2: The SDQ subsc } \\
\text { income and marital status } \\
\text { SDQ, Strengths and Difficu }\end{array}$ & nal. & $\begin{array}{l}\text { OQ subs } \\
\text { yses). } \\
\text { separat } \\
\text { es). }\end{array}$ & calles st & & 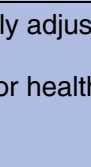 & th hat & & ackgrol & tranoun & & side & & & $\begin{array}{l}\text { scation, } \\
\text { s' educa }\end{array}$ & \\
\hline
\end{tabular}

that measures of association are often found to be less sensitive than prevalence estimates to incomplete follow-ups. ${ }^{38}$

Our results according to previous findings, and interpretation of findings

Health behaviours

The relationship between smoking in adolescence and receipt of health-related benefits in young adults is not well explored, but a Swedish study of men at the age of conscription Johansson $e t a l^{15}$ studied educational differences in relation to disability pension and also focused on the role of health behaviour in late adolescence. They reported that the hazard of disability pension increased when comparing smokers with non-smokers, and health-related lifestyle factors attenuated the association between education and disability pension. ${ }^{15}$ Smoking is associated with other unhealthy behaviours and mental health. ${ }^{21}$ In our study, the association between smoking and benefits weakened when adjusting for sociodemographic variables, other health behaviours and mental health but remained an independent risk factor for health-related benefits. Review articles have emphasised the importance of smoking as a risk factor for mental health problems in adolescence. ${ }^{39}{ }^{40}$ In another paper with a sample including some of the adolescents in the present study, beginning smoking between 15 and 18 years was associated with mental distress at age $18 .^{21}$
Others have also found adolescents' smoking to have a longitudinal influence on adult mental health and to predict harmful effects on social, emotional and behavioural well-being in adulthood. ${ }^{41}$ One possible explanation for the association between smoking at age 15 years and receiving health-related benefits in young adulthood in this observational study may be later mental health problems. Psychiatric disorders are the main reason for receiving health-related benefits in Norway. ${ }^{4}$

In girls, we found that never using alcohol (abstaining) compared with some use of alcohol increased the hazard for medical benefits. The same tendency was present among boys, but was statistically insignificant in the multivariable analysis. Weekly use of alcohol increased the hazard of receiving medical benefits compared with some use of alcohol among boys. In studies among adults and young men at the age of conscription, abstainers were reported to be at a higher risk of disability pension or sickness absence compared with light or moderate drinkers, ${ }^{8} 94243$ and high consumers were also reported to be at a higher risk than light or moderate consumers. 891342 A plausible explanation for the J-shaped association was put forward by Skogen et at $t^{42}$ who studied drinking habits and disability pensions in a Norwegian cohort of adults (The Nord-Trøndelag Health Study; HUNT). They found some support for 'sick quitters' among abstainers. In our population of 
young adults, the probability of individuals having stopped drinking alcohol because of illness is low. In fact, this study reports drinking habits at the early age of 15-16 years probably representing exploration and social attitudes. However, in a study of change in young people's alcohol consumption during the transition to early adulthood (19-28 years), respondents clearly tend to maintain their relative drinking position over time. ${ }^{44}$ Leifman et $a t^{45}$ compared 18-19-year-old male abstainers with moderate alcohol consumers on social and emotional maturity, and physical and mental health, and found that abstainers scored higher than moderate consumers on several indicators of poor sociability, including feeling insecure in the company of others, being unpopular in school, never having intimate conversations with friends, having a lower degree of emotional control and a higher prevalence of mental disorders. We adjusted for various symptoms of mental health problems in model 4, but this did not change the estimates markedly. Other characteristics of abstainers may explain the increased hazard among the abstainers compared with moderate users in our study.

We found that physical activity in mid-adolescence decreased the hazard of receiving health-related benefits in the early twenties compared with inactivity. A Finnish study of 14-year-olds and 16-year-olds followed up to the age of 28-38 years reported a positive association between physical activity and socioeconomic position at follow-up. ${ }^{46}$ School performance was found to mediate these associations, especially among girls. In a previous paper, we found that physical activity in 10th grade was negatively associated with dropping out from upper secondary school. ${ }^{47}$ We have little knowledge about the possible influences of physical activities on school performance, particularly in the long term, ${ }^{48}$ and the possible effects on later socioeconomic position and long-term use of health-related benefits have been even less studied. One possible explanation for this association may be that success in physical activity may confer self-confidence and make people believe in themselves and consequently strive for higher levels of education and socioeconomic position, which is associated with a lower use of benefits. Physical activity may also act as an empowering or buffering factor, protecting young people from stress and poor health. Physical activity positively influences health and fitness, reduces the risk of several diseases and promotes mental health and wellbeing. ${ }^{49}$ A study focusing on physical activity and use of health-related benefits among adults showed that leisuretime physical activity for 20 min or more at least once a week was associated with a lower risk of sick leave. ${ }^{5}$

\section{Mental health}

The hazard of receiving health-related welfare benefits in young adulthood rose with increasing levels of conduct problems, hyperactivity-inattention problems, emotional symptoms and peer problems in adolescence after controlling for sociodemographic factors and health behaviours. The findings for emotional symptoms are in line with studies from New Zealand showing that the number of depressive episodes in adolescence was associated with later self-reported welfare dependence after adjustment for confounding factors and comorbidity. ${ }^{17}$ In a study with an outcome measure similar to that of our study, Pape et $a l^{16}$ reported that anxiety and depression symptoms in adolescence increased the susceptibility of receiving medical benefits in early adulthood in a Norwegian sample. In a British population-based adolescent sample, teacher-reported externalising behaviour was associated with financial difficulties in adult life (after 40 years). ${ }^{19}$ This association persisted after adjustments for father's social class, cognitive ability and depression or anxiety in adolescence. In another study from New Zealand, Fergusson and Horwood $^{50}$ found that conduct problems at age 8 years were associated with unemployment by 18 years after adjusting for possible individual, family and sociodemographic confounders. One mechanism for these associations is that adolescents with mental health problems have an increased risk of mental illness later in life, ${ }^{18} 50$ which may be the direct cause of work impairment. It is also possible that the linkage between adolescent mental health and later outcomes may be mediated by intervening variables. Mental health problems in adolescents may impair their ability to learn and create a risk for lower education attainment and school dropout, ${ }^{47}$ which in turn are known to increase benefit dependence. ${ }^{51}$ In the study by Fergusson and Horwood ${ }^{50}$ in which they studied conduct problems at age 8 years and unemployment 10 years later, analyses suggested that the association was mediated by a series of processes during adolescence including patterns of peer affiliation, substance use, truancy and problems with school authority. It is also possible that the relationship between mental health in adolescence and later outcomes reflects the presence of confounding variables and of previous problems or disease. More general personal traits such as childhood temperament and intellectual abilities are other potentially important factors, ${ }^{15}{ }^{52}$ but the effects of intellectual function and psychiatric disease seem to be independent of each other. ${ }^{14}$

\section{Conclusion and implications}

Our study found that smoking, alcohol intake, physical activity and various mental health problems in adolescence were associated with an increased hazard of receiving medical benefits on entering adulthood. More research is needed to better understand the underlying mechanisms for the observed associations. Specifically, we need more knowledge of potential mediating factors that could be a focus for interventions. School engagement/attendance may be such mechanisms which require further research. Additionally, future research may also investigate the reasons for receipt of medical benefits and focus on disabilities that have onset during adulthood, or those that are potentially preventable. 
Author affiliations

${ }^{1}$ Centre for Child and Adolescent Mental Health, Eastern and Southern Norway, Oslo, Norway

${ }^{2}$ Norwegian Centre for Violence and Traumatic Stress Studies, Oslo, Norway

${ }^{3}$ National Centre for Dual Diagnosis, Innlandet Hospital Trust, Sanderud, Norway

${ }^{4}$ Faculty of Public Health, Hedmark University College, Elverum, Norway

Acknowledgements The questionnaire studies (The Youth Studies) were carried out by the Norwegian Institute of Public Health.

Contributors Ås was active in planning the study, conception and design of the manuscript, as well as analysing and interpreting the data and drafting the manuscript. SH was involved with the conception and design of the manuscript, as well as discussing the analyses and data interpretation and critical review of the manuscript. TW-L participated in the conception and design of the manuscript, analyses and critical review of the manuscript. LL was involved with the conception and design of the manuscript, as well as discussing the analyses and data interpretation and critical review of the manuscript.

Funding This work was supported by the Research Council of Norway, Grant number 202492. The questionnaire studies (The Youth Studies) were funded by the Norwegian Institute of Public Health.

Competing interests None declared.

Patient consent Obtained.

Ethics approval Permission to use survey data was given by The Norwegian Institute of Public Health. The study was approved by the Regional Committee for Medical and Health Research Ethics and by the Norwegian Data Inspectorate.

Provenance and peer review Not commissioned; externally peer reviewed.

Data sharing statement No additional data are available.

Open Access This is an Open Access article distributed in accordance with the Creative Commons Attribution Non Commercial (CC BY-NC 4.0) license, which permits others to distribute, remix, adapt, build upon this work noncommercially, and license their derivative works on different terms, provided the original work is properly cited and the use is non-commercial. See: http:// creativecommons.org/licenses/by-nc/4.0/

\section{REFERENCES}

1. OECD. Off to a good start?: jobs for youth. Paris: OECD, 2010.

2. OECD. Jobs for youth, Norway. Paris: OECD, 2008.

3. Sawyer SM, Afifi RA, Bearinger LH, et al. Adolescence: a foundation for future health. Lancet 2012;379:1630-40.

4. Brage S, Bragstad T. Unge på arbeids- og helserelaterte ordninger. Oslo: Arbeids- og velferdsdirektoratet, 2011.

5. Eriksen W, Bruusgaard D. Physical leisure-time activities and long-term sick leave: a 15-month prospective study of nurses' aides. J Occup Environ Med 2002;44:530-8.

6. Bertera RL. The effects of behavioral risks on absenteeism and health-care costs in the workplace. J Occup Med 1991;33:1119-24.

7. Upmark M, Karlsson G, Romelsjo A. Drink driving and criminal behaviours as risk factors for receipt of disability pension and sick leave: a prospective study of young men. Addiction 1999;94:507-19.

8. Upmark M, Moller J, Romelsjo A. Longitudinal, population-based study of self reported alcohol habits, high levels of sickness absence, and disability pensions. J Epidemiol Community Health 1999;53:223-9.

9. Sidorchuk A, Hemmingsson T, Romelsjo A, et al. Alcohol use in adolescence and risk of disability pension: a 39 year follow-up of a population-based conscription survey. PLOS ONE 2012;7:e42083.

10. Allebeck P, Mastekaasa A. Swedish Council on Technology Assessment in Health Care (SBU). Chapter 5. Risk factors for sick leave-general studies. Scand J Public Health 2004;63:49-108.

11. Moncrieff $J$, Pomerleau J. Trends in sickness benefits in Great Britain and the contribution of mental disorders. J Public Health Med 2000;22:59-67.

12. Mykletun A, Overland S, Dahl AA, et al. A population-based cohort study of the effect of common mental disorders on disability pension awards. AJ Psychiatry 2006;163:1412-18.
13. Upmark M, Lundberg I, Sadigh J, et al. Psychosocial characteristics in young men as predictors of early disability pension with a psychiatric diagnosis. Soc Psychiatry Psychiatr Epidemiol 1999;34:533-40.

14. Gravseth HM, Bjerkedal T, Irgens LM, et al. Influence of physical, mental and intellectual development on disability in young Norwegian men. Eur J Public Health 2008;18:650-5.

15. Johansson $E$, Leijon $O$, Falkstedt $D$, et al. Educational differences in disability pension among Swedish middle-aged men: role of factors in late adolescence and work characteristics in adulthood. $J$ Epidemiol Community Health 2012;66:901-7.

16. Pape $\mathrm{K}$, Bjorngaard $\mathrm{JH}$, Holmen $\mathrm{TL}$, et al. The welfare burden of adolescent anxiety and depression: a prospective study of 7500 young Norwegians and their families: the HUNT study. BMJ Open 2012;2:e001942.

17. Fergusson DM, Boden JM, Horwood LJ. Recurrence of major depression in adolescence and early adulthood, and later mental health, educational and economic outcomes. Br J Psychiatry 2007;191:335-42.

18. Fergusson DM, Woodward LJ. Mental health, educational, and social role outcomes of adolescents with depression. Arch Gen Psychiatry 2002;59:225-31.

19. Colman I, Murray J, Abbott RA, et al. Outcomes of conduct problems in adolescence: 40 year follow-up of national cohort. BMJ 2009;338:a2981.

20. Bardone AM, Moffitt T, Caspi A, et al. Adult mental health and social outcomes of adolescent girls with depression and conduct disorder. Dev Psychopathol 1996;8:811-29.

21. Lien L, Sagatun Å, Heyerdahl S, et al. Is the relationship between smoking and mental health influenced by other unhealthy lifestyle factors? Results from a 3-year follow-up study among adolescents in Oslo, Norway. J Adolesc Health 2009;45:609-17.

22. Skogen JC, Sivertsen B, Lundervold AJ, et al. Alcohol and drug use among adolescents: and the co-occurrence of mental health problems. Ung-Hordaland, a population-based study. BMJ Open 2014;4:e005357.

23. Sagatun A, Sogaard AJ, Bjertness E, et al. The association between weekly hours of physical activity and mental health: a three-year follow-up study of 15-16-year-old students in the city of Oslo, Norway. BMC Public Health 2007;7:155.

24. Norwegian Institute of Public Health. Youth Studies 2000-2009. Secondary Youth Studies 2000-2009. 22 March 2013. http://www.fhi. no/artikler/?id=105586

25. Brage $\mathrm{S}$, Thune $\mathrm{O}$. Medisinske årsaker til uføreytelser blant unge 1977-2006. In: Arbeid og velferd, ed. Arbeids-og velferdsdirektoratet. Oslo: Arbeid- og velferdsdirektoratet, 2008:28-36.

26. Goodman R. The strengths and difficulties questionnaire: a research note. J Child Psychol Psychiatry 1997;38:581-6.

27. Youthinmind. Information for researchers and professionals about the Strengths \& Difficulties Questionnaires. Secondary Information for researchers and professionals about the Strengths \& Difficulties Questionnaires 1 January 2012. http://www.sdqinfo.com/

28. Goodman A, Goodman R. Strengths and difficulties questionnaire as a dimensional measure of child mental health. J Am Acad Child Adolesc Psychiatry 2009;48:400-3. [Erratum appears in J Am Acad Child Adolesc Psychiatry. 2009;48(4):581].

29. Lie B. Immigration and immigrants 2002. Oslo: Statistics Norway, 2002

30. Statistics Norway. Norwegian Standard Classification of Education (NOS C 751). 1 January 2008. http://www.ssb.no/english/subjects/ 04/90/nos_c751_en/nos_c751_en.pdf

31. Statistics Norway. Income and Property Statistics for Households 2002 (NOS D 310). 2 January 2008. http://www.ssb.no/emner/05/01/ nos_inntektformue/nos_d310/nos_d310.pdf

32. Harrell FE. Regression modeling strategies: with applications to linear models, logistic regression, and survival analysis. New York: Springer, 2001.

33. Therneau TM, Grambsch PM. Modeling survival data: extending the Cox model. New York: Springer, 2000.

34. Goodman R. Psychometric properties of the strengths and difficulties questionnaire. J Am Acad Child Adolesc Psychiatry 2001;40:1337-45.

35. Goodman A, Lamping DL, Ploubidis GB. When to use broader internalising and externalising subscales instead of the hypothesised five subscales on the Strengths and Difficulties Questionnaire (SDQ): data from British parents, teachers and children. J Abnorm Child Psychol 2010;38:1179-91.

36. Thoresen M. A note on correlated errors in exposure and outcome in logistic regression. Am J Epidemiol 2007;166:465-71.

37. Szklo M. Epidemiology: beyond the basics. Sudbury: Jones and Bartlett, 2007

38. Bjertness $\mathrm{E}$, Sagatun $\AA$, Green $\mathrm{K}$, et al. Response rates and selection problems, with emphasis on mental health variables and DNA 
sampling, in large population-based, cross-sectional and longitudina studies of adolescents in Norway. BMC Public Health 2010;10:602.

39. Williams JM, Ziedonis D. Addressing tobacco among individuals with a mental illness or an addiction. Addict Behav 2004;29:1067-83.

40. Park S, Romer D. Associations between smoking and depression in adolescence: an integrative review. Taehan Kanho Hakhoe Chi 2007;37:227-41.

41. Mathers M, Toumbourou JW, Catalano RF, et al. Consequences of youth tobacco use: a review of prospective behavioural studies. Addiction 2006;101:948-58.

42. Skogen JC, Knudsen AK, Mykletun A, et al. Alcohol consumption, problem drinking, abstention and disability pension award. The Nord-Trondelag Health Study (HUNT). Addiction 2012;107:98-108.

43. Salonsalmi A, Laaksonen M, Lahelma E, et al. Drinking habits and sickness absence: the contribution of working conditions. Scand $J$ Public Health 2009;37:846-54.

44. Pape H, Hammer T. Sober adolescence-predictor of psychosocial maladjustment in young adulthood? Scand J Psychol 1996;37:362-77.

45. Leifman $\mathrm{H}$, Kuhlhorn $\mathrm{E}$, Allebeck $\mathrm{P}$, et al. Abstinence in late adolescence-antecedents to and covariates of a sober lifestyle and its consequences. Soc Sci Med 1995;41:113-21.
46. Koivusilta LK, Nupponen H, Rimpela AH. Adolescent physical activity predicts high education and socio-economic position in adulthood. Eur J Public Health 2012;22:203-9.

47. Sagatun A, Heyerdahl S, Wentzel-Larsen T, et al. Mental health problems in the 10th grade and non-completion of upper secondary school: the mediating role of grades in a population-based longitudinal study. BMC Public Health 2014;14:16.

48. Taras H. Physical activity and student performance at school. J Sch Health 2005;75:214-18.

49. Bouchard C, Blair SN, Haskell WL. Physical activity and health Champaign, IL: Human Kinetics, 2006.

50. Fergusson DM, Horwood LJ. Early conduct problems and later life opportunities. J Child Psychol Psychiatry 1998;39: 1097-108.

51. De Ridder KA, Pape K, Johnsen R, et al. School dropout: a major public health challenge: a 10-year prospective study on medical and non-medical social insurance benefits in young adulthood, the Young-HUNT 1 Study (Norway). J Epidemiol Community Health 2012;66:995-1000.

52. Henderson M, Hotopf M, Leon DA. Childhood temperament and long-term sickness absence in adult life. $\mathrm{Br} J$ Psychiatry 2009;194:220-3. 